\title{
Microsystem technologies: foreword to special issue on design, test, integration and packaging of MEMS/MOEMS, 2009
}

\author{
Bernard Courtois • Bernd Michel
}

Received: 29 March 2010/Accepted: 29 March 2010/Published online: 16 May 2010

(C) Springer-Verlag 2010

The symposium on design, test, integration and packaging of MEMS/MOEMS (DTIP) was held in Rome, Italy, 1-3 April 2009, as a follow up to previous issues held in 1999 and 2000 in Paris, France, in 2001, 2002, 2003 in Mandelieu-La Napoule, France, in 2004 and 2005 in Montreux, Switzerland, and in 2006, 2007 in Stresa, Italy and in 2008 in Nice. This series of symposia is a unique single-meeting event expressly planned to bring together participants interested in manufacturing microstructures and participants interested in design tools to facilitate the conception of these microstructures. The symposium is traditionally composed of two conferences running in parallel: one on CAD, design and test (CDT), and another one on microfabrication, integration and packaging (MIP). In addition, participants of both conferences can attend invited talks and Workshops/special sessions.

This special issue is collecting reviewed and unabridged versions of papers presented at the symposium. The papers have been again refereed, along the usual refereeing process in force at Microsystem Technologies. We are proud to offer these papers to the readers of this journal now.
From 38 revised papers submitted to this Special Issue, 31 papers have been finally selected. They cover a broad range of topics. They appear in the special issue in the following order. Three papers on 3D integration, four papers on modeling and simulation, two papers on bioMEMS, five papers on devices and components, one paper on thermal evaluation, five papers on integrated processes, five papers on manufacturing, four papers on characterization, and two papers on assembly technologies.

We hope that you'll enjoy these contributions as much as we did.<smiles>C#CC#CCC</smiles>

Bernard Courtois

DTIP Chair and Guest Editor, MST

B. Mild

Bernd Michel

Editor-in-Chief, MST

B. Courtois $(\square)$

Grenoble, France

e-mail: dtip@imag.fr

B. Michel

Berlin, Germany 